\begin{tabular}{c}
\hline TÜRK \\
TARIM ve DOĞA BILIMLERI \\
DERGISI \\
\hline \hline
\end{tabular}

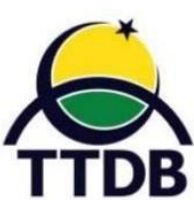

www.dergipark.gov.tr/turkjans Araştırma Makalesi

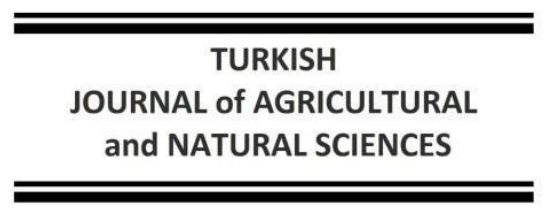

\title{
Bazı Bitki Büyüme Düzenleyicileri Uygulamalarının Vakkas Üzüm Çeşidine Ait Çeliklerin Köklendirilmesi ve Fidan Randımanına Etkisi
}

\author{
Fırat işLEK ${ }^{1}$, Ahmet YENIKALAYCI ${ }^{2}$, Ali BAYRAM ${ }^{3}$, Atilla ÇAKIR ${ }^{4 *}$ \\ 1,2,3 Muş Alparslan Üniversitesi, Uygulamalı Bilimler Fakültesi,+ Bitkisel Üretim ve Teknolojileri Bölümü/Muş, \\ Türkiye \\ ${ }^{4}$ Bingöl Üniversitesi, Ziraat Fakültesi, Bahçe Bitkileri Bölümü/Bingöl, Türkiye \\ *Sorumlu yazar: cakiratilla@gmail.com
}

Geliş Tarihi: 01.08.2021 Düzeltme Geliş Tarihi: 10.09.2021 Kabul Tarihi: 14.10.2021

\section{Öz}

Bu çalışma; 2021 yılında, Muş ili için önemli üretim ve gelir kaynağı olan Vakkas üzüm çeşidi çeliklerinin köklenme performansı ve fidan randımanını belirlemek amacıyla yürütülmüştür. Çalışmada kullanılan çeliklere Kontrol grubunun yanı sıra İndol-3-Bütirik Asit (IBA) ve İndol-3-Asetik Asit (IAA) bitki büyüme düzenleyicilerinden üç farklı uygulama dozları (1000 ppm, 2000 ppm ve 3000 ppm) olmak üzere toplam 7 uygulama gerçekleştirilmiştir. Denemeye alınan bitki materyallerinde, sürgün sayısı (adet), sürgün uzunluğu $(\mathrm{cm})$, yaprak sayısı (adet), kök sayısı (adet), kök uzunluğu $(\mathrm{cm})$, kök yaş ağırlığı (gr), kök gelişim seviyesi (1-4 skalası), sürmüş/sürmemiş çelikler ve fidan randımanı (\%) bakımından değerlendirilmiştir. Çalışma sonucunda elde edilen fidanlarda ortalama sürgün sayısı (2 adet), kök sayısı (46.67 adet), kök uzunluğu $(17.63 \mathrm{~cm})$, kök yaş ağırlığı (9.30 gr), kök gelişim seviyesi (3.67), ve fidan randımanında (\%92) en iyi başarı 1000 ppm IBA uygulamasından elde edilmiştir. Ortalama sürgün uzunluğu $(23.33 \mathrm{~cm})$ ve yaprak sayısında (18.33 adet) en başarılı uygulama 2000 ppm IBA uygulaması olarak tespit edilmiştir. Sonuç olarak, IBA dozlarının uygulandığı çeliklerde kontrol grubu ve IAA dozlarının uygulandığı çeliklere kıyasla daha olumlu sonuçlar alındığı tespit edilmiştir.

Anahtar Kelimeler: IAA, IBA, Tüplü asma fidanı, Vakkas üzümü

\section{The Effect of Some Plant Growth Regulators Applications on Rooting and Seedling Performance of Cuttings of Vakkas Grape Variety}

\begin{abstract}
In this study; In 2021, it is aimed to produce quality seedling from the cuttings of Vakkas grape variety, which is an important production and income source for the province of Muş. In he study; the effects of 7 applications, including the control group, Indole Butyric Acid (IBA) and Indole Acetic Acid (IAA) plant growth regulators tree different application doses (1000 ppm, 2000 ppm and 3000 ppm), on the seedling growth were investigated. The paremeters of shoot number (piece), shoot length $(\mathrm{cm})$, leaf number (piece), root number (piece), root length $(\mathrm{cm})$, root fresh weight $(\mathrm{g})$, root development level (1-4 scale), seedling performance (\%) were evaluated in plant meteryal study. End of the study number of shoots (2 number), number of roots (46.67 number), root length $(17.63 \mathrm{~cm})$, root fresh weight $(9.30 \mathrm{~g})$, root development level (3.67), and seedling performance (92\%) the best success was obtained from 1000 ppm IBA application. The most successful application was determined as $2000 \mathrm{ppm}$ IBA application in average shoot length $(23.33 \mathrm{~cm})$ and number of leaves (18.33 piece). It was determined that more positive results were obtained in the cuttings to which IBA doses were applied, compared to the control group and the cuttings to which IAA doses were applied.
\end{abstract}

Keywords: IAA, IBA, Tubed vine seedling, Vakkas grape 


\section{Giriş}

Dünya bağcılığında önemli bir yere sahip olan ülkemiz, üretim ve yetiştiricilikte birçok sorun ile karşılaşmaktadır. Başlıca sorunlar; kıraç alanların bağcılıkta kullanımı, genel olarak susuz bağcılık yapılır fikri, mekanizasyon ve teknolojinin bağcılıkta yeteri kadar kullanılmaması ve yeteri kadar asma üretilmemesi olarak ele alınabilir (Çakır ve Yücel, 2016a; Çakır ve Yücel, 2016b; Çakır ve Yücel, 2017) Kaliteli, sağlıklı ve bölge şartlarına uygun doğru fidan üretiminin yetersiz olması bağ tesisinde ve üzüm yetiştiriciliğinde karşılaşılan sorunların temelini oluşturmaktadır (Çelik ve ark., 2010; Söylemezoğlu ve ark., 2010;).

Asma fidanlarının üretim şekilleri; tüplü ve açık köklü olarak iki şekilde sınıflandırmak mümkündür (Çelik ve ark., 1998). Tüplü asma fidanı üretimde maliyet açık köklü asma fidanı üretimine kıyasla daha fazladır (Uysal ve Ateş 2014). Tüplü asma fidanı üretiminde 1,5-2 ay kadar bir süre içerisinde araziye şaşırtılmaya hazır duruma gelmektedir fakat açık köklü fidanların araziye şaşırtılması için yaklaşık bir yıl gibi bir süre gerekmektedir (Şen ve Yağcı, 2015). Tüplü asma fidanlarının üretimi ile bağcılıkta ihtiyaç duyulan fidanların hızlı bir şekilde üretimi mümkün olmaktadır (Şen ve Yağcı, 2015).

Ülkemizde, Tüik 2019 verilerine göre; 405.438 ha alanda yıllık 4 milyon 100 bin ton yaş üzüm üretimi yapılmakta olup, üzüm üretimi toplam meyve üretimimiz içerisinde de önemli bir paya sahiptir (Anonim, 2020).

Yetiştiricilik yapılan bağın ekonomik ömrünün ortalama 40 yıl olduğu varsayılırsa, çeşitli literatürlere göre; ülkemizdeki fidan ihtiyacının yıllık 7.5-15 milyon aralığında olduğu düşünülmektedir (Şen ve Yağcı, 2015).

Asma fidanı üretiminde kök sayısı; kullanılan anaç ve çeşitten (Samancı ve Uslu, 1992), köklendirme ortamından (Sivritepe ve Türkben, 2001), tüp büyüklügünden (Akman ve Ilgın 1990) ve benzer birçok faktör tarafından etkilenmektedir.

Asma fidanı üretiminde sürgün uzunlukları; anaca, çeşide, katlama ortamına, köklenme ortamına, hormon seviyesine, çelik ve kalemin beslenme durumuna, fidanların bakım koşullarına ve mikoriza uygulamalarına göre (Kelen, 1994; Cangi, 1999;

Kelen ve Demirtaş, 2001; Kılıç, 2013) değişebilmektedir. Sürgün uzunluğunun; katlamadan yeni çıkarılmış aşılı çeliklerde dahi kullanılan anaca ve çeşide bağlı olarak farklılık gösterebileceği de bildirilmiştir (Bekişli ve ark., 2015)
Muş yöresinde yetiştirilen Vakkas üzümü 18001900 yıllarında Sovyetler Birliğinden Muş iline getirilerek dikildiği, bölge ekolojisine iyi uyum sağladığı, kaliteli ve verimli üzüm üretimi bilinmektedir (Anonim, 2021a, b). Muş Yöresinde bağcılığın gelişmeye başlaması ve bağ alanlarının artması ile mahzenlerde toplanan şıralar Fransa'ya ihraç edilerek Dünyaca ünlü Bordo şarabı yapımında kullanılmıştır (Anonim b). Bu yıllarda yetiştirilmeye başlanan, üreticiler tarafından ürünleri kaliteli olarak bildirilen yerli asma çeşitleri; bölge halkının önemli gelir kaynaklarından biri olmakla birlikte, bölge ekonomisinde önemli bir yere sahiptir. Fakat zamanla yörede bağ alanları önemli ölçüde azalmış ve buna bağlı olarak üretim de düşmüştür.

Bu çalışma; asma fidanı üretiminde sorun olan kalite ve fidan randımanı düşüklügünü ortadan kaldırmaya yönelik bitki büyüme düzenleyicileri (hormon) uygulamalarının etkilerini belirlemek amacıyla yapılmıştır. Muş ili bağcılığının yeniden geliştirilmesi, eski önemini kazanması ve kent ekonomisine katkı sağlaması konusunda bir ön çalışma olması hedeflenmiştir.

\section{Materyal ve Yöntem}

Çalışma Muş Alparslan Üniversitesi, Tıbbi ve Aromatik Bitkiler Uygulama Merkezi Serasında, 2021yılında yürütülmüştür. Çalışmada bitkisel materyal olarak; Vitis vinifera L. türüne ait Vakkas üzüm çeşidi çelikleri kullanılmıştır.

Muş İli çiftçi bağlarından budama döneminde (Şubat sonu/Mart başı) alınan 350 adet çelik dikim dönemine kadar serin $\left(+4{ }^{\circ} \mathrm{C}\right)$ ve nemli (\%.95 bağıl nem) ortamda muhafaza edilmiştir. Daha sonra alınan çelikler; $35 \mathrm{~cm}$ uzunlukta ve her çeliğin uç kısmında 2 göz kalacak şekilde çelikler hazırlanmıştır. Ardından çelikler tesadüfi olarak 7 gruba ayrılmıştır. Her bir grupta yer alan çeliklere farklı uygulamalar yapılmıştır. Bunlar; kontrol (uygulamasız), 3 farklı dozda indol-3- bütirik asit (IBA) ve 3 farklı dozda indol-3- asetik asit (IAA) uygulamalarıdır. Deneme deseni olarak tesadüf parselleri deneme deseni kullanılmıştır. Buna göre; her uygulamaya ait grupta yer alan çelikler 5 tekerrüre ayrılmış ve her tekerrürde 10'ar çelik olacak şekilde düzenlenmiştir. Köklendirme ortamı olarak perlit:torf $(1: 1 \mathrm{v} / \mathrm{v})$ siyah polietilen torbalar içerisine konularak tüplü ortam hazırlanmıştır.

\section{Çeliklerin köklendirme ortamına dikilmesi ve bakım işlemleri}

Birinci grup (kontrol grubu) için 50 adet çelik herhangi bir uygulama yapılmadan köklendirilme 
ortamına bırakılmıştır, ikinci grup için IBA 3 farklı dozda (1000 ppm, 2000 ppm, 3000 ppm) hazırlanan çözeltiler içerisine 3 sn kadar süre ile hızlı daldırma yapılarak çelikler köklendirme ortamına dikilmiştir. Üçüncü grup için IAA 3 farklı dozda (1000 ppm, 2000ppm ve 3000 ppm) hazırlanan çözeltiler içerisine 3 sn kadar süre ile hızlı daldırma yapılarak çelikler köklendirme ortamına çelikler dikilmiştir. Söz konusu her uygulama için 50'şer adet çelik kullanılmıştır. Çeliklerin dikimi nisan ayının ikinci haftasında gerçekleştirilmiştir. Çeliklerin yer aldığı tüpler, dikimden itibaren ilk 10 gün sabah akşam, diğer zamanlarda her gün sabah saatlerinde ve her tüpe yaklaşık $200 \mathrm{ml}$ su verilerek sulama işlemi gerçekleştirilmiştir. Haziran ayının son haftasında (yaklaşık 2 ay) deneme tamamlanmış ve ölçümler yapılmıştır.

\section{Incelenen özellikler}

Sürgün sayısı (adet): Fidan üzerinde yer alan gözlerden teşekkül eden sürgünler sayılarak adet cinsinden belirlenmiştir (Çoban ve Kara, 2003).

Sürgün uzunluğu (cm): Sürgünün ucundan, sürgünün çıkış noktasına kadar; şerit metre yardımıyla ölçümü yapılıp, $\mathrm{cm}$ cinsinden ifade edilmiştir (Bekişli ve ark., 2015; Gursoz ve ark., 2017).

Yaprak sayısı (adet): Sürgün üzerinde meydana gelen normal büyüklüğünün 1/3'ü kadar büyümüş olan yapraklar tam yaprak olarak değerlendirilmiş ve buna göre yaprak sayısı tespit edilip adet olarak ifade edilmiştir (Çakır ve Yücel 2016a).

Kök sayısı (adet): Farklı uygulamalara tabi tutulmuş çeliklerden elde edilen fidanların; söküm sonrasında köklerinin yıkanması sonrasında, 1 cm'den uzun olan kökleri sayılarak adet cinsinden belirlenmiştir (Çelik, 2021).

Kök uzunluğu (cm): Farklı hormon uygulamalarına tabi tutulmuş çeliklerden elde edilen fidanların; sökümü takiben köklerinin yıkanması sonrasında, kök uzunlukları cetvel yardımıyla $\mathrm{cm}$ cinsinden belirlenmiştir (Odabaşıoğlu ve ark., 2018).

Kök yaş ağırlığı (gr): Farklı hormon uygulamalarına tabi tutulmuş çeliklerden elde edilen fidanların köklerinin yaş ağırlıkları; söküm ve yıkama ve nemlerinin alınmasını takiben, $\pm 0.001 \mathrm{~g}$ duyarlılıktaki hassas terazide gr cinsinden belirlenmiştir (Demirtaş, 2018).
Kök gelişim seviyesi (0-4): Farklı ortamlarda büyüyen fidanların kök gelişimleri Çizelge 1'deki 04 skalasına göre değerlendirilmiştir (Çelik, 1982).

Çizelge 1. Kök gelişim seviyesi

\begin{tabular}{ll}
\hline Skala Değeri & Gelişim Seviyesi \\
\hline 0 & Hiç köklenmeyen \\
1 & Tek yönlü köklenme \\
2 & İki taraflı köklenme \\
3 & Üç taraflı köklenme \\
4 & Çepeçevre köklenme \\
\hline
\end{tabular}

Fidan randımanı (\%): Köklendirme ortamında canlılığını koruyarak fidana dönüşen çelik sayısı $x$ 100/Başlangıçta dikilen toplam çelik sayısı formülü yardımıyla belirlenmiştir (Odabaşıoğlu ve ark., 2018).

Fidanların sınıflandırılması: Sürgün ve kök gelişme durumları TS 3981'e göre (Anonim, 1995) değerlendirilerek fidanlar I. ve II. boy olarak gruplandırılmıştır.

\section{İstatistik Analiz}

Deneme 5 tekerrürlü, her tekerrürde 10'ar fidan kullanılacak şekilde; Tesadüf Parselleri deneme desenine göre düzenlenmiş, varyans analizi ile uygulamalar arası farklılık ise \%5 önem seviyesinde Duncan testinden yararlanılarak "SPSS version 13.0" istatistik paket programı kullanılarak gerçekleştirilmiştir.

\section{Bulgular}

Çalışmada sürgün uzunluğu $(\mathrm{cm})$, Sürgün sayısı (adet) ve yaprak sayısı ile ilgili veriler Çizelge 2'de verilmiştir. Çizelge 2 incelendiğinde; uygulamalar arasında, sürgün uzunluğu ve yaprak sayısı bakımından farklılık istatistiki olarak önemli bulunurken sürgün sayısı önemsiz bulunmuştur.

2000 ppm IBA uygulanan fidanlardan en yüksek sürgün uzunluğu ve yaprak sayısı ortalaması elde edilirken, en yüksek sürgün sayısı ortalaması 1000 ppm IBA uygulaması yapılan fidanlarda gözlenmiştir. Uygulamalar arasında kontrol grubu olarak belirlenen fidanlardan en düşük sürgün uzunluğu, sürgün sayısı ve yaprak sayısı ortalaması elde edilmiştir. 
Çizelge 2. Tüplü fidanların sürgün uzunluğu, sürgün sayısı, yaprak sayısı

\begin{tabular}{|c|c|c|c|}
\hline Uygulamalar & Sürgün Uzunluğu (cm) & Sürgün Sayısı (adet) & Yaprak Sayısı (adet) \\
\hline Kontrol & $8,00 \pm 2,082 c$ & $1,33 \pm 0,333$ & $5,33 \pm 0,333 c$ \\
\hline 1000 ppm IAA & $10,67 \pm 1,764 c$ & $1,67 \pm 0,333$ & $10,67 \pm 4,177 a b c$ \\
\hline 2000 ppm IAA & $10,67 \pm 0,882 c$ & $1,67 \pm 0,333$ & $7,67 \pm 0,333 \mathrm{bc}$ \\
\hline 3000 ppm IAA & $13,67 \pm 2,028 b c$ & $1,67 \pm 0,333$ & $12,33 \pm 2,848 a b c$ \\
\hline 1000 ppm IBA & $23,00 \pm 2,646 a$ & $2,00 \pm 0,000$ & $15,33 \pm 3,528 a b$ \\
\hline 2000 ppm IBA & $23,33 \pm 0,882 \mathrm{a}$ & $1,67 \pm 0,333$ & $18,33 \pm 2,186 a$ \\
\hline 3000 ppm IBA & $18,33 \pm 2,333 a b$ & $2,00 \pm 0,000$ & $14,00 \pm 1,155 a b$ \\
\hline$P_{\text {değerleri: }}$ & 0,01 & 0,68 & 0,03 \\
\hline \multicolumn{4}{|c|}{$\rightarrow$ a. b. c: Aynı sütunda farklı küçük harfi alan "Uygulamalar” arası fark önemlidir ( $p<0.05)$. } \\
\hline \multicolumn{2}{|c|}{$\begin{array}{l}\text { Çalışmaya konu olan kök uzunluğu, kök sayısı, kök } \\
\text { yaş ağırlığı, kök gelişim seviyesi değerleri Çizelge } \\
\text { 3'te, sürmüş/sürmemiş çelikler ile fidan randımanı } \\
\text { ise Çizelge } 4 \text { 'te verilmiştir. Çizelge } 3 \text { incelendiğinde } \\
\text { uygulamalar arasında fark kök sayısı ve kök yaş } \\
\text { ağırlığı ortalaması bakımından farklılık istatistiki } \\
\text { olarak önemli, kök uzunluğu ve kök gelişim seviyesi } \\
\text { ise önemsiz bulunmuştur. }\end{array}$} & \multicolumn{2}{|c|}{$\begin{array}{l}\text { Tüplü fidanların kök uzunluğu, kök sayısı, kök yaş } \\
\text { ağırlığı, kök gelişim seviyesi parametreleri } \\
\text { bakımından en yüksek değerlerin ortalaması genel } \\
\text { olarak } 1000 \text { ppm IBA uygulaması ile elde edilmiştir. } \\
\text { En düşük değerin ortalaması ise kök uzunluğu ve } \\
\text { kök sayısı parametrelerinde kontrol grubu ve } 1000 \\
\text { ppm IAA uygulamasında, kök yaş ağırlığı ve kök } \\
\text { gelişim seviyesi parametrelerinde kontrol } \\
\text { grubunda tespit edilmiştir (Çizelge } 3 \text { ). }\end{array}$} \\
\hline
\end{tabular}

Çizelge 3. Tüplü fidanların kök uzunluğu, kök sayısı, kök yaş ağırlığı, kök gelişim seviyesi ortalaması

\begin{tabular}{|c|c|c|c|c|}
\hline Uygulama & Kök Uzunluğu (cm) & Kök Sayısı (adet) & Kök Yaş Ağırlığı (gr) & Kök Gelişim Seviyesi (0-4) \\
\hline Kontrol & $13,33 \pm 1,764$ & $11,33 \pm 0,882 \mathrm{c}$ & $1,87 \pm 0,186 \mathrm{c}$ & $2,33 \pm 0,333$ \\
\hline 1000 ppm IAA & $13,33 \pm 1,453$ & $11,33 \pm 1,453 \mathrm{c}$ & $2,50 \pm 0,404 c$ & $2,67 \pm 0,333$ \\
\hline 2000 ppm IAA & $15,00 \pm 1,732$ & $13,33 \pm 1,764 \mathrm{c}$ & $3,03 \pm 0,867 c$ & $3,00 \pm 0,577$ \\
\hline 3000 ppm IAA & $14,33 \pm 2,186$ & $23,00 \pm 5,508 b c$ & $4,33 \pm 1,202 b c$ & $3,33 \pm 0,667$ \\
\hline 1000 ppm IBA & $17,67 \pm 0,882$ & $46,67 \pm 8,819 a$ & $9,30 \pm 1,940 \mathrm{a}$ & $3,67 \pm 0,333$ \\
\hline 2000 ppm IBA & $15,00 \pm 0,577$ & $35,67 \pm 2,963 a b$ & $7,17 \pm 0,441 a b$ & $3,67 \pm 0,333$ \\
\hline 3000 ppm IBA & $14,33 \pm 0,882$ & $40,00 \pm 4,163 b$ & $8,00 \pm 0,577 a$ & $3,67 \pm 0,333$ \\
\hline$P_{\text {değerleri: }}$ & 0,45 & 0,01 & 0,01 & 0,24 \\
\hline \multicolumn{5}{|c|}{$\rightarrow$ a. b. c: Aynı sütunda farklı küçük harfi alan “Uygulamalar” arası fark önemlidir ( $p<0.05)$. } \\
\hline \multirow{2}{*}{\multicolumn{3}{|c|}{$\begin{array}{l}\text { Çizelge } 4 \text { incelendiğinde en fazla sürmüş fidan } \\
\text { sayısı ve oranı } 1000 \text { ppm IBA uygulaması yapılan } \\
\text { fidanlardan elde edilirken en az sürmüş fidan sayısı } \\
\text { ve oranı ise } 1000 \mathrm{ppm} \text { IAA uygulamasında tespit } \\
\text { edilmiştir. Ayrıca } 5 \mathrm{~cm} \text { 'den uzun sürgün uzunluğuna }\end{array}$}} & \multicolumn{2}{|c|}{$\begin{array}{l}\text { sahip 1. sınıf olarak kabul edilen fidanların oranı ve } \\
\text { sayısı incelendiğinde, yine aynı uygulamalar olan } \\
1000 \text { ppm IBA uygulamasında en yüksek değer elde } \\
\text { edilirken } 1000 \text { ppm IAA uygulamasında da en } \\
\text { düşük değer elde edilmiştir. }\end{array}$} \\
\hline & & & \multicolumn{2}{|c|}{ Çizelge 4. Tüplü fidanların fidan randımanı (\%) } \\
\hline Uygulamalar & & rmüş & 1. sınif & 2. sinıf \\
\hline \multirow{2}{*}{ Kontrol } & Sayı & 9 & 31 & 10 \\
\hline & $\%$ & 18 & 62 & 20 \\
\hline
\end{tabular}




\begin{tabular}{lll}
\hline \multirow{2}{*}{1000 ppm IAA } & Sayı & 30 \\
& $\%$ & 60 \\
2000 ppm IAA & Sayı & 40 \\
& $\%$ & 80 \\
3000 ppm IAA & Sayı & 32 \\
& $\%$ & 64 \\
1000 ppm IBA & Sayı & 46 \\
2000 ppm IBA & $\%$ & 92 \\
& Sayı & 43 \\
3000 ppm IBA & $\%$ & 86 \\
& Sayı & 44 \\
\hline
\end{tabular}

\section{Tartışma ve Sonuç}

Elde edilen bulgular genel olarak değerlendirildiğinde; IBA dozlarının uygulandığı çeliklerde, kontrol (uygulama yapılmamış çelikler) grubu ve IAA dozlarının uygulandığı çeliklere kıyasla daha olumlu sonuçlar alındığı söylenebilmektedir. Çeliklerin kök uzunluğu, kök sayısı, kök yaş ağırlı̆̆ı, kök gelişim seviyesi, sürgün sayısı ve fidan randımanında en iyi başarı 1000 ppm IBA uygulamasından elde edilmiştir. Sürgün uzunluğu ve yaprak sayısında en başarılı uygulama 2000 ppm IBA uygulaması olarak tespit edilmiştir. 1000 ppm IAA uygulamasının kontrol grubuna kıyasla önemli bir etkisinin olmadığı görülmüştür.

Nitekim, Nautiyal ve Purohit (1986) IBA ve IAA dozlarının çeliklerin köklenmesi ve kök uzunlukları üzerine yaptıkları bir çalışmada IBA uygulaması kök uzunluğu ve köklenmede daha başarılı olduğunu bildirmişlerdir. Yapılan bir başka çalışmada Epstein ve Müller (1993), IBA uygulamasının IAA uygulamasına kıyasla kök oluşumunu arttırma kabiliyetinin daha başarılı olduğunu bildirmişlerdir. Ehrlinger ve Howel (1981)'de 9 çeşit asma fidanı üzerinde yaptığı çalışmada 6 çeşit asma fidanında 3000 ppm IBA uygulamasının kök sayısını artırdığını bildirmişlerdir. Kelen ve Demirtaş (2001), perlit:kum ortamına dikilmiş $420 \mathrm{~A}$ anacında 1000, 2000 ve 3000 ppm IBA hızlı daldırma uygulaması ile yüzde köklenme, kök uzunluğu, kök sayısı ve kök yaş ağırlığı değerlerinin kontrole kıyasla arttığını tespit etmiştir. Kara ve ark. (1998), de 5000 ppm den başlayan IBA dozlarını 41 B anacında kullanmış ve olumlu sonuçlar almışlardır. Hartmann ve ark. (1997), çeliklerin köklendirilmesinde en iyi oksin hormonunun IBA olarak kabul edildiğini bildirmişlerdir dahası Kaşka ve Yılmaz (1974), en

güvenilir ve en iyi oksin hormonunun IBA olduğunu bildirmişlerdir. Bunun nedeni olarak da IBA uygulamalarının, geniş konsantrasyon sınırları

$\begin{array}{lll}20 & 20 & 10 \\ 40 & 40 & 20 \\ 10 & 32 & 8 \\ 20 & 64 & 16 \\ 18 & 25 & 7 \\ 36 & 50 & 14 \\ 4 & 42 & 4 \\ 8 & 84 & 8 \\ 7 & 28 & 15 \\ 14 & 56 & 30 \\ 6 & 39 & 5 \\ 12 & 78 & 10\end{array}$

içerisinde toksik olmadığı ve ayrıca birçok bitki türünün köklenmelerini teşvik bakımından yeterli etkide bulunabileceği bildirilmiştir. Literatürdeki çalışmalar genel olarak değerlendirildiğinde, IBA uygulamalarının çeliklerin köklendirilmelerinde daha başarılı olduğu görülmektedir. Çalışmalarda elde edilen sonuçlar bu çalışma ile elde edilen sonuçlarla paralellik göstermektedir. Önceki çalışmalar ve bu çalışmadan elde edilen bulgular göstermiştir ki; ülkemizin yıllık intiyacı olarak kabul edilen 7.5-15 milyon adet asma fidanı ihtiyacının karşılanması ve iyi kök yapısına sahip kaliteli fidan üretimi için asma fidanı üretiminde, IAA yerine IBA dozlarının kullanılması daha uygundur. Ayrıca; asma fidanı üretiminde köklenmeyi teşvik eden ve kök gelişimini arttıran diğer büyümeyi düzenleyicilerin ve bitki gelişimini destekleyici mikroorganizmaların (PGPB) da gelecek çalışmalarda incelenmesi önem arz etmektedir.

\section{Teşekkür}

Bu çalışma Muş Alparslan üniversitesi BAP birimi tarafından BAP-20-UBF-4901-12 No'lu "Vakkas Üzüm Bağlarının Çeliklerinin Köklendirilmesi ve Yaygınlaştırılması" başlıklı preje tarafından desteklenmiştir.

Çıkar Çatışması Beyanı: Makale yazarları aralarında herhangi bir çıkar çatışması olmadığını beyan ederler.

Araştırmacıların Katkı Oranı Beyan Özeti: Yazarlar makaleye eşit oranda katkı sağlamış olduklarını beyan ederler.

\section{Kaynaklar}

Akman, I.., Ilgın, C. ve Kacar, N. 1989. Çeliklerin Dikimden Önce Suda Bırakılma Sürelerinin ve Parafinli Parafinsiz Dikimin Fidan Randıman ve Kalitesine Etkisi. Manisa Bağcılık Araştırma Enstitüsü, Yay. No: 33/1: 19. 
Anonim, 2021a. http://www.mus.gen.tr/haber32227-mus-mus-uzumu-tezgaha-indihaberi.html. Erişim tarihi: 09.09.2021.

Anonim, 2021b. http://www.mus.gov.tr/musuzumu-mus. Erişim tarihi: 09.09.2021.Anonim, 2020 http://www.tuik.gov.tr/PreTablo.do?alt_i $\mathrm{d}=1001$ (Erişim Tarihi:25.05.2020)

Anonim, 1995. TS 3981 Asma Fidanı. TSE, Ankara.

Bekişli, M.í., Gürsöz, S., Bilgiç, C., 2015. Aşılı Asma Fidanı Üretiminde Bazı Anaç-Çeşit Kombinasyonlarının Katlama Odası Performanslarının İncelenmesi. Harran Tarım ve Gıda Bilimleri Dergisi, 19(1), 2437.

Cangi, R., Kelen, M. ve Dogan, A. 1999. Serin İklim Koşullarında Asma Fidanı Üretim Olanakları. Türkiye III. Ulusal Bahçe Bitkileri Kongresi, Eylül 1999, 430-435, Ankara.

Çakır, A. ve Yücel, B. 2016a. Aşılı Tüplü (Kaplı) Asma Fidanı Üretiminde Farklı Köklendirme Ortamlarının Kök ve Sürgün Gelişimi Üzerine Etkileri. Türk Doğa ve Fen Dergisi, $5(2), 18-25$

Çakır, A. ve Yücel, B. 2016b. Narince ve Kalecik Karası Üzüm Çeşitlerinin 1103 Paulsen Amerikan Asma Anacı ile Aşı Performansının Belirlenmesi. Türk Tarım ve Doğa Bilimleri Dergisi, 3(4), 311-317.

Çakır, A. ve Yücel, B. 2017. Aşılı Tüplü (Kaplı) Asma Fidanı Üretiminde Farklı Köklendirme Ortamlarının Fidan Randımanı Üzerine Etkileri. Meyve Bilimi, 4(1), 1-5.

Çelik, H. 1982. Kalecik Karası/41B aşı kombinasyonu için sera koşullarında yapılan aşılı köklü fidan üretiminde değişik köklenme ortamları ve NAA uygulamalarının etkileri. Doçentlik Tezi, Ankara Üniversitesi, Ziraat Fakültesi, 73, Ankara.

Çelik, H., Ağaoğlu, Y.S., Fidan, Y., Marasalı, B., ve Söylemezoğlu, G., 1998. Genel Bağcılık. Sunfidan A.Ş. Mesleki Kitaplar Serisi, No:1, Ankara, 253s.

Çelik, H., Kunter, B., Söylemezoğlu, G., Ergül, A., Çelik, H., Karataş, H., Özdemir, G. ve Atak, A. 2010. Bağcılığın geliştirilmesi yöntemleri ve üretim hedefleri. TMMOB Ziraat Mühendisleri Odası VII. Teknik Kongresi. Bildiriler Kitabı-1, 493-513.
Çelik, M. ve Tekintaş, F.E. 2004. Bazı Budama Uygulamalarının Sultani Çekirdeksiz Üzüm Çeşidinde Kuru Üzüm Kalitesine, Çelik Özelliklerine ve Mineral Madde Alımına Etkileri. Adnan Menderes Üniv. Ziraat Fak. Derg. 1:35-40. Aydın.

Çelik, T., 2021. Farklı Anaçlara Aşılı Bazı Sofralık Üzüm Çeşitlerinde Boğum Düzeyine Bağlı Olarak Vegetatif Gelişmenin İncelenmesi. Harran Üniversitesi, Fen Bilimleri Enstitüsü, Yüksek Lisans Tezi, Şanlıurfa, 72 s.

Çoban, H. ve Kara, S. 2003. Bazı üzüm (Vitis vinifera L.) Çeşitlerinin Asma Anaçları ile Aşı Tutma Durumu ve Fidan Kalitesine Etkileri Üzerine Araştırmalar. Anadolu Ege Tarımsal Araştırmalar Enstitüsü Dergisi, 13(1): 176-187.

Demirtaş, G., 2018. Bazı Üzüm Çeşitlerinin (Vitis vinifera L.) Farklı Konsantrasyonlardaki Tuz Stresine $(\mathrm{NaCl})$ Tolerans Sınırlarının Belirlenmesi. Harran Üniversitesi, Fen Bilimleri Enstitüsü, Yüksek Lisans Tezi, Şanlıurfa, 56s.

Ehrlinger, D. ve Howell, G. 1981. Differential rooting of hardwood cuttings from different grape cultivars. Plant Propagator 27: 13-15

Epstein, E. ve Ludwig-Müller, J. 1993. Indole-3butyric acid in plants: occurrence, synthesis, metabolism and transport. Physiologia Plantarum, 88(2):382-389.

Ergenoğlu, F. ve Tangolar, S. 1990. Aşılı Çeliklerde Köklenme, Aşı Yerinde Kallus Oluşumu ve Sürgün Büyümesi ile İlgili Araştırmalar. Çukurova Üniversitesi Ziraat Fakültesi Dergisi, 5 (2); 141-156

Gursoz, S., Odabasıoglu, M.I., Ak, B.E., 2017. A Study on The Grafting of Different Table Grape Varieties on Different Rootstocks. The $3^{\text {rd }}$ International Conference on Engineering and Natural Sciences (ICENS), 03-07 May 2017, Budapest-Hungary, 888$893 p$.

Hartmann, H.T., Kester, D.E., Davies, F.T. ve Geneve, R.L. 1997. Plant propagation principles and practices. Prentice Hall, New Jersey, USA, 770

Kara, S., Altındişli, A. ve Aşkın, A. 1998. Farklı köklendirme ortamlarının ve IBA dozlarının sisleme ünitesi altında 41 B anacının köklenmesine etkileri üzerine bir 
araştırma. IV. Bağcılık Sempozyum Bildirileri: 354- 356. 20-23 Ekim 1998. Yalova.

Kaşka, N. ve Yılmaz, M. 1974. Bahçe Bitkileri Yetiştirme Tekniği. Çukurova Üniversitesi, Ziraat Fakültesi Yayın No: 79, Ders Kitabı No: 52, Adana.

Kelen, M. 1994. Bazı Uygulamalar Aşılı - Köklü Asma Fidanı Üretiminde Fidan Kalite ve Randımanı Üzerine Etkileri ve Aşı Kaynaşmasının Anatomik ve Histolojik Olarak İncelenmesi Üzerine Araştırmalar. Yüzüncü Yıl Üniversitesi, Fen Bilimleri Enstitüsü, Bahçe Bitkileri Anabilim Dalı Doktora Tezi, Van.

Kelen, M. ve Demirtaş, i. 2001. 5 BB ve 420 A Amerikan Asma Anaçlarının Köklenme Oranları ve Kök Kaliteleri Üzerine Farklı Köklendirme Ortamları ile IBA Dozlarının Etkileri. Ankara Üniversitesi Tarım Bilimleri Dergisi 7(1):142- 146

Kılıç, D. 2013. Kokteyl Mikoriza Uygulamalarının Aşılı Asma Fidanı Üretiminde Fidan Randıman ve Kalitesi Üzerine Etkileri. Goü Fen Bilimleri Enstitüsü, Doktora Tezi.

Nautiyal, P.C. ve Purohit, A.N. 1986. Effect of auxin on seasonal rooting response of stem cuttings of Berberis species from different altitudes. Indian Journal of Plant Physiology, 24(3): 286-290

Odabaşıŏlu, M.í., Karaca Sanyürek, N., Çakır, A., Söylemezoğlu, G., 2018. Elektroşok Uygulamalarının Aşılı Asma Fidanı Üretiminde Fidan Gelişimine Etkileri. Bahçe, 47(Özel Sayı): 363-372.

Samancı, H, ve Uslu, ì. 1992. Aşılı - Köklü Asma Fidanı Üretiminde Randıman ve Kalitenin Çeşit Anaç Kombinasyonlarına Göre Değişiminin Araştırılması. Sonuç Raporu, Alata Bahçe Kültürleri Araştırma Enstitüsü.

Sivritepe, N. ve Türkben, C. 2001. Müşküle Üzüm Çeşidinde Farklı Anaçların Aşıda Müşküle Üzüm Çeşidinde Farklı Anaçların Aşıda Başarı ve Fidan Randımanı Üzerine Etkileri. Ulud. Üniv. Zir. Fak. Derg., 15:47-58.

Söylemezoğlu, G., Dumanoğlu, H., Çelik, H., Kunter, B., Atıcı, A. ve Tahmaz, H. 2010. Türkiye'de Asma ve Meyve Fidanı Üretimi ve Kullanımı. TMMOB ZMO Ziraat Mühendisliği VII. Teknik Kongresi, 11-15 Ocak 2010, Ankara, Bildiriler Kitabı Cilt-2: s891-907.
Şen, A ve Yağcı, A. 2015. Tüplü Asma Fidanı Üretiminde Farklı Köklendirme Yerlerinin Fidan Randımanı Ve Kalitesi Üzerine Etkileri. Meyve Bilimi. 3(1): 22-28s.

Uysal, H ve Ateş, F. 2014. Sultani Çekirdeksiz Üzüm Çeşidinde Tüplü Asma Fidanı Üretiminin Maliyet Analizi. Meyve Bilimi. 1(2): 55-58s. 